Article

\title{
An Intelligent Iris Based Chronic Kidney Identification System
}

\author{
Sohail Muzamil ${ }^{1,2, *(1)}$, Tassadaq Hussain ${ }^{1,3, *} \mathbb{D}$, Amna Haider ${ }^{3} \mathbb{D}$, Umber Waraich ${ }^{3,4}$, \\ Umair Ashiq ${ }^{2}$ and Eduard Ayguadé 5 (i) \\ 1 Department of Electrical Engineering, Riphah International University, Islamabad 46000, Pakistan \\ 2 Department of Electrical and Computer Engineering, Abbottabad Campus, \\ COMSATS University Islamabad, Khyber Pakhtunkhwa, Abbottabad 22060, Pakistan; \\ umairashiq@cuiatd.edu.pk \\ 3 UCERD Pvt Ltd. Islamabad, Islamabad 44000, Pakistan; amna@ucerd.com (A.H.); \\ umberwarraich@uet.edu.pk (U.W.) \\ 4 Department of Biomedical Engineering, Narowal Campus, University of Engineering and Technology \\ Lahore, Punjab, Narowal 54890, Pakistan \\ 5 Barcelona Supercomputing Center(BSC-CNS), E08034 Barcelona, Spain; Eduard.ayguade@bsc.es \\ * Correspondence: sohail_muzamil@cuiatd.edu.pk (S.M.); tassadaq@ucerd.com (T.H.)
}

Received: 20 November 2020; Accepted: 8 December 2020; Published: 12 December 2020

check for updates

\begin{abstract}
In recent years, the demand for alternative medical diagnostics of the human kidney or renal is growing, and some of the reasons behind this relate to its non-invasive, early, real-time, and pain-free mechanism. The chronic kidney problem is one of the major kidney problems, which require an early-stage diagnosis. Therefore, in this work, we have proposed and developed an Intelligent Iris-based Chronic Kidney Identification System (ICKIS). The ICKIS takes an image of human iris as input and on the basis of iridology a deep neural network model on a GPU-based supercomputing machine is applied. The deep neural network models are trained while using 2000 subjects that have healthy and chronic kidney problems. While testing the proposed ICKIS on 2000 separate subjects (1000 healthy and 1000 chronic kidney problems), the system achieves iris-based chronic kidney assessment with an accuracy of $96.8 \%$. In the future, we will work to improve our AI algorithm and try data-set cleaning, so that accuracy can be increased by more efficiently learning the features.
\end{abstract}

Keywords: iridology; health-care; embedded computer vision; artificial intelligence

\section{Introduction}

The prime function of the human urinary system [1] is to eliminate waste materials and products from the body. In order to maintain homeostasis, the kidney plays an important role in the urinary system. The waste materials; mineral [2], vitamin [3], nitrogenous waste [4], ammonia [5], and creatinine [6] are converted into urine, which is taken out of the body through ureters, bladder, and urethra [1]. Some other functions of the urinary system include: the regulation of plasma ionic composition [7], plasma volume [8], secretion of hormones, plasma hydrogen ion concentration $(\mathrm{pH})$, and plasma osmolarity [9].

The kidney disorder leads to: (a) diabetes, (b) hypertension, (c) hereditary (inheritance), (d) urological, (e) acute renal failure, (f) infection of the urinary tract, kidney (g) glomerular disease, and (h) vascular renal [10-13]. Aforesaid problems increase the risk of major fatal problems, such as: cardiovascular issues [14], human immunodeficiency virus "HIV" [15], and malaria [16].

The death rate due to kidney failure from 2005 to 2013 is increased by 32\% [17]. In 2010, 2.3 to 7.1 million people lost their lives because of non-accessibility to kidney dialysis [18]. Approximately 
1.7 million people died annually only due to acute kidney injuries [19]. The World Health Organization (WHO) report published in 2018 revealed that overall 5-10 million people lost their lives due to urinary disorders [20]. These statistics show that kidney related diseases are increasing day-by-day.

Chronic kidney disease is one of the major problems of the urinary system. Other kidney-related problems are: (1) Autosomal Dominant Polycystic Kidney Disease (ADPKD) [21], which is a genetic disorder that is caused by the growth of numerous cysts in the kidneys; (2) the long term inflammation and scarring of the glomeruli known as chronic glomerulonephritis (CGN) [22]; (3) chronic interstitial nephritis (CIN) [23], in which swelling occurs in between the kidney tubules; and, (4) renovascular disease (RVD) [24], which is related to the arteries to the kidneys.

Figure 1 describes the percentage of chronic kidney problems in underdeveloped countries (like Pakistan), where most of the population is affected by Chronic Glomerulonephritis (CGN). The main cause of CGN is either the genetic transfer of the problem or the immune system problem. The body mistakenly attacks its own cells due to the immune system problem [25]. Diabetic nephropathy is another serious kidney problem that is caused by high blood glucose levels [26]. Diabetic nephropathy is next to CGN, affecting $23 \%$ of the population. Chronic Interstitial Nephritis (CIN) is also one of the major kidney problem with $17 \%$ affectees, this problem has many different etiologies, which are categorized based on problem-specific findings.

In conventional medical procedures, pathological markers, abnormalities in the blood or urine, imaging tests, and Glomerular Filter Rate (GFR) may reveal the kidney problems. According to the Kidney Disease Outcomes Quality Initiative (K/DOQI) of the National Kidney Foundation (NKF), the reasons for chronic kidney disease could be: (a) kidney damage or (b) a decrease in GFR to $60 \mathrm{~mL} / \mathrm{min} . / 1.73 \mathrm{~m}^{2}$ or less, for three or more than three-months [27]. The best available method for estimating GFR is to determine the level of creatinine in blood and urine [28]. The major causes of chronic kidney failure are the delayed diagnosis, financial problems of the patient, and the unavailability of expert doctors in remote areas [29,30]. The earlier detection of chronic kidney disease can reduce the morbidity [31] and mortality rate [32,33].

Alternative medicine [34] and early diagnoses [35] are the need and demand for future healthcare technology. This is because it provides the non-invasive, and real-time diagnoses of human dysfunctional organs to improve health quality. The usage of an alternative pre-diagnosis method [36] can save complications, cost, and delay diagnosis. Iridology [37] or iris study is an alternative diagnosing method that is used to pre-diagnose human dysfunctional organs. Iridology categorizes the human iris according to each organ of the body [38]. The weakness or damage of an organ is reflected by the marks, spots, or patterns in the corresponding iris region [39]. These iris-patterns indicate the problems of the specific body organs [40]. For instance, if there is a problem with the stomach, then it shows changes in the iris around the pupil. Similarly, changes in kidneys appear at the bottom edge of the iris. The right iris indicates the organs on the right side of the human body, while the left side of the iris reflects the organs on the left side of the body. Figure 2 shows different regions that are related to almost all human body organs or functions [41].

In this proposed research work, we develop an Iris-based Chronic Kidney Identification System (ICKIS) for an early assessment of kidney problems. The ICKIS takes iris images as input and performs general pre-diagnosis for chronic kidney organ disorder that is based on an iridology chart and artificial intelligent algorithm. The algorithm is executed on a GPU-based supercomputing machine. The ICKIS determines the severity of damage of the human kidney by identifying the texture and color of mark or lesion (in the iris kidney region) while using a CNN based artificial intelligence algorithm. The ICKIS is executed on GPU based supercomputing system. While testing ICKIS on 2000 (healthy and kidney problems) subjects, the results confirm that the ICKIS identified the chronic kidney problem with an accuracy of $96.8 \%$. The proposed ICKIS system would help clinicians to perform quick and early pre-diagnoses of the human chronic kidney that would not only save time, but also decrease the financial burden over the patients and the national health system. The proposed technique will open a new paradigm in the field of medicine by providing cost-effective, quick, and painless pre-diagnosis. 


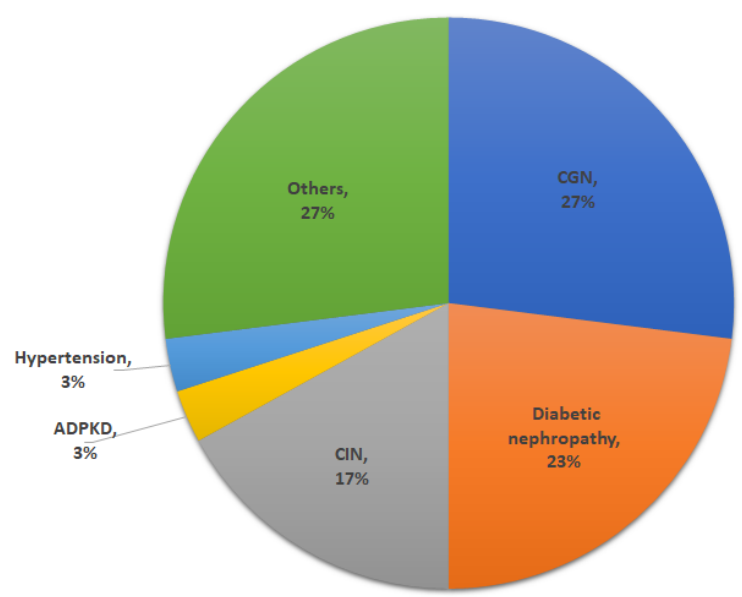

Figure 1. Pie chart showing percentage chronic kidney diseases in Pakistan [42].
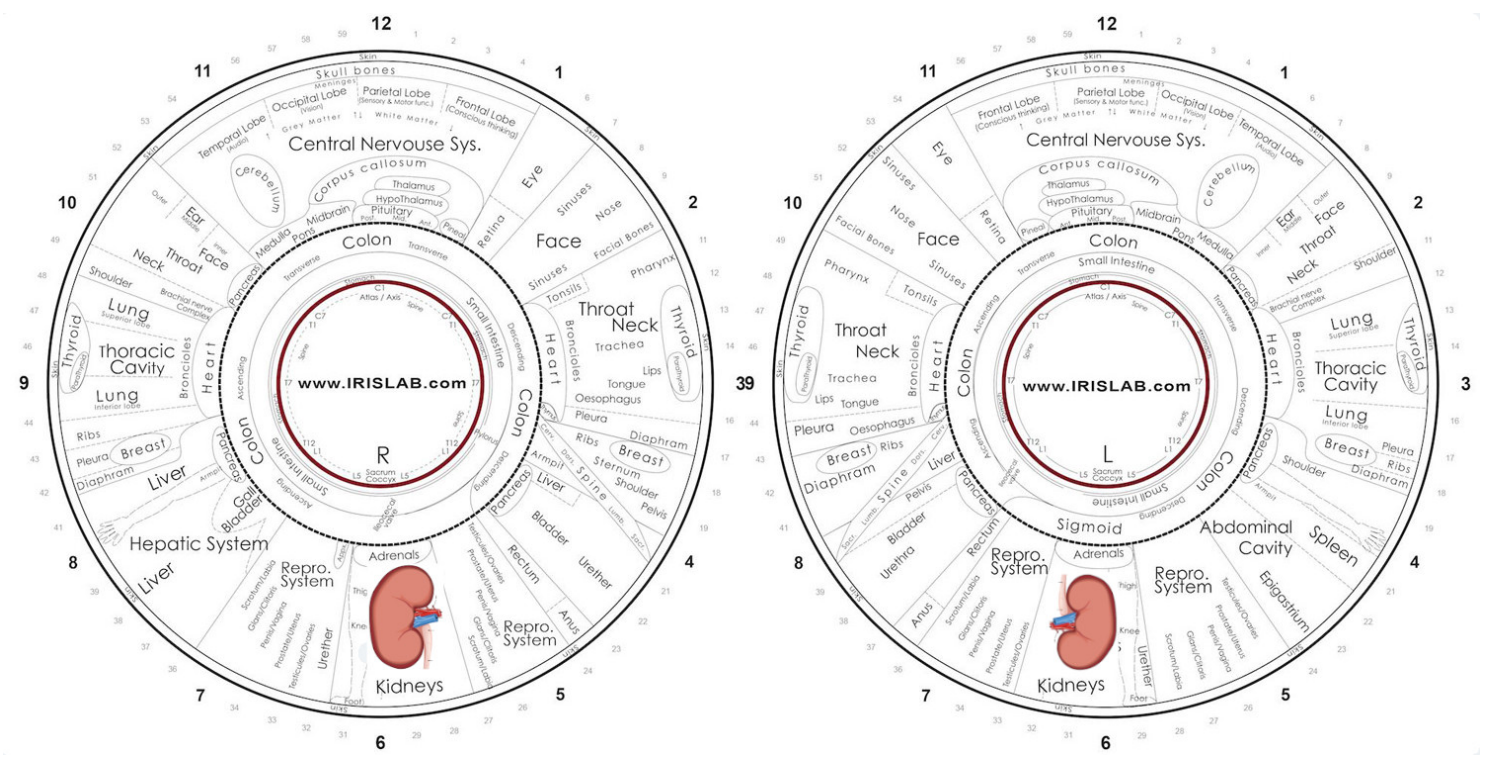

Figure 2. Iridology Chart: Showing Kidney Region of Interest in Left and Right Irides.

\section{Related Work}

Various research has been conducted on the human iris to identify human health dysfunctionalities and iridology effectiveness.

SE. Hussein et al. [39] use iridology to diagnose kidney problems and focus on Chronic Renal Failure (CRF). The multiplex Handheld camera is used to get iris images of 340 subjects, among them 168 do not have CRF while 172 having CRF (tested by creatinine test). Different techniques are used for segmentation and normalization, such as (a) Circular Hough Transform (CHT) [43], (b) Homogeneous Rubber Sheet Model (RSM), and (c) Gabor Filter. Features are being extracted while using 2D-wavelet Transform and, for classification, an Adaptive Neuro-Fuzzy Inference System is used. The CRF is found $82 \%$ and $93 \%$ correctly for each subject having kidney problems or not, respectively. This proposed research gives promising results for the pre-diagnosis of kidney CRF.

To diagnose medical conditions, Sara Amerifar et al. [44] have performed research work while using human irises. The CASIA iris image database has been used during the research work. In order to detect circular shapes, CHT is used, while Hessian analysis is used for geometrical enhancement [45]. Multiscale blobness [46] is used to spot out different sizes in the iris region of the kidney region and connected component labeling is done in order to group pixels of the candidate region. Their results confirm that the algorithm identified a subject with CRF and no-CRF with an accuracy of $82 \%$ and $93 \%$, respectively. 
Agus Prayitno et al. [47] undertake their studies on kidney complications that are caused by diabetes. The iris region of interest (ROI) is used according to the iridology chart. To analyze the ROI, color constancy [48] and independent component analysis [49] are used. They use Dino-Lite Ver. 2.0 for capturing iris images. The results show that $76 \%$ of patients are diabetic with kidney complications. The results of the proposed system are verified by the patient medical creatinine level.

Adhi et al. [50] classify the last stage of kidney CRF using the iridology chart. They capture iris images of 82 subjects using the Dino-Lite Digital iris scope AMH-RUT camera system having $1.3 \mathrm{M}$ pixels resolution and 30 frame rate. The watershed method for feature segmentation is used in order to examine the broken tissues in the iris. The author uses the mean of the gradient, mean of the watershed, mean of watershed binary, and size of broken tissue as features, which are inputted to Support Vector Machine (SVM) for machine learning-based classification. During the research, 61 hemodialyses and 21 healthy patients are used for analysis and the results show that the algorithm identified hemodialysis patients with an accuracy of $87.5 \%$.

Samant and Agarwal [51] use different machine learning techniques, including (a) Binary Tree model, (b) SVM, (c) Adaptive Boosting model, (d) Neural Network, and (e) Random Forest model for classification and diagnosis of diabetes. Aforesaid techniques use Iris-SCAN-2 with cross-match technology to obtain gray infrared images for the investigation of (a) statistical, (b) texture, and (c) discrete wavelet-based features. The authors perform modified CHT to extract the aforementioned features. Rubber-sheet normalization is used to map iris features on fixed rectangular representation. They divided 338 patients into two groups, one having a sign of diabetes include 180 subjects, and the other with no sign have 158. The results confirm that the model identified diabetes with an accuracy of $89.63 \%$.

Rossi Erwin et al., in [52], use iridology to develop a database for colon disorder. Autonomic Nervous Wreath (ANW) of the iris is focused on digestive problems. Hough transform and RSM are used for feature extraction. Sixty subjects are used, in which 25 are controlled while 35 are proven colon disorder. The results show an $8 \%$ error. This research shows progressive results and concludes that, to obtain better and reliable results, a large data-set is required.

Jamal et al. [53] work to develop a tool for detecting diabetes through the corresponding region of the pancreas organ, while using color coding and visual inspection. Segmentation is done by Daugman's approach and normalization is done while using RSM; adaptive histogram equalization of the spatial domain method, which directly operates on pixels, is used for image enhancement. Features of $20 \times 20$ ROI are extracted while using Principal Component Analysis (PCA). Feed forward-back propagation based, Artificial Neural Network is applied for classification with the Levengurg-Marquardt back-propagation for weight and bias of network as training function. Out of 10 subjects, eight subjects are identified as diabetic subjects. Later on, all of these eight are verified as diabetic type II using an insulin normality test. $100 \%$ accuracy is achieved for the pancreas organ.

UCERD Private Limited [54], Iridology Research Group [55], has developed imaging system architecture [56] and algorithms [57] for iridology based dysfunctional organs identification. The group proposed intelligent algorithms for health-care. It uses high-performance architecture $[58,59]$ that manages an enormous volume of patient images $[60,61]$ information, and effectively uses them to make a decision.

\section{Methodology: An Intelligent Iris Based Chronic Kidney Identification System}

This section explains the methodology of the Iris-based Chronic Kidney Identification System (ICKIS). The section is subdivided into four main sections: the Kidney Pathology, the Iris-Acquisition System, the Processing System, and the Artificial Intelligence (AI) Algorithm.

\subsection{Kidney Pathology}

The section explains the pathology of the kidney against chronic kidney disease while using conventional methods and iridology techniques. 


\subsubsection{Conventional Method}

Conventional methods use Glomerular Filtration Rate (GFR), in order to determine the stage of chronic kidney disease. In GFR, samples of the patient's blood and urine are compared. A test for creatinine using the blood sample is conducted in order to measure GFR (if creatinine value increases, the GFR decreases).

GFR measures milliliters of waste that is filtered by kidneys in a minute. The kidneys of a healthy person filter over $90 \mathrm{~mL}$ of waste per minute [27]. The following are the stages of chronic kidney disease concerning the GFR described by the Kidney Disease Outcome Quality Initiative (K/DOQI) [62]:

Stage1: (GFR $>90 \mathrm{~mL} / \mathrm{min}$. $/ 1.73 \mathrm{~m}^{2}$ ) kidney functioning is normal up to $90 \%$, but with minor damage (protein in urine).

Stage 2: (GFR 60-89 mL/min. $/ 1.73 \mathrm{~m}^{2}$ ) Acute Kidney Disease, mild loss in kidney functioning, and it is working up to 60 to $89 \%$.

Stage 3: (GFR 30-59 mL/min./1.73 $\mathrm{m}^{2}$ ) Chronic Kidney Disease, moderate loss of kidney functioning, and it is decreased to 45 to $59 \%$, but it may lead to a moderate to severe loss of kidney functioning, up to 30 to $44 \%$.

Stage 4: (GFR 15-29 mL/min./1.73 $\mathrm{m}^{2}$ ) Severe Chronic Disease, severe loss of kidney functioning from 15 to $29 \%$.

Stage 5: (GFR $\left.<15 \mathrm{~mL} / \mathrm{min} . / 1.73 \mathrm{~m}^{2}\right)$ End-Stage Renal Disease (ESRD) i.e., kidney failure stage. At this stage, there is a total loss or less than $15 \%$ functioning.

The GFR level keeps on changes with time for different age groups. In these early stages, GFR alone does not secure the finding that's why other kidney inspection tests like (a) blood, (b) urine, and (c) kidney scan can be used in order to determine the kidney anomalies. In stage 4 and stage 5, the severe symptoms are being felt by the patients, which leads him/her to chronic kidney failure. In this research work, patients who are grouped under stages 4 and 5 are focused, as indicated by their GFR, and the emphasis is on the presence or absence of chronic kidney disease of stage 4 and stage 5 .

\subsubsection{Iridology}

In the light of clinical assessments from patient data and reports, various patterns and features for chronic kidney are illustrated by utilizing the iridology chart (shown in Figure 2). The iridology chart that is shown in Figure 2 is divided into 12 or $\left(360^{\circ}\right)$ portions. The targeted portion for chronic kidney disease (CKD) against stage 4 and stage 5 lies under position $5.35-5.95\left(252^{\circ}-268^{\circ}\right)$ for the right eye and in positions $6.05-6.60\left(272^{\circ}-288^{\circ}\right)$ for the left eye. The right eye represents the right renal organ and the left eye represents the left renal organ. Figure 3 shows the region of interest (ROI) and stage 4 and 5 , marks and patterns for both the left and right eyes.

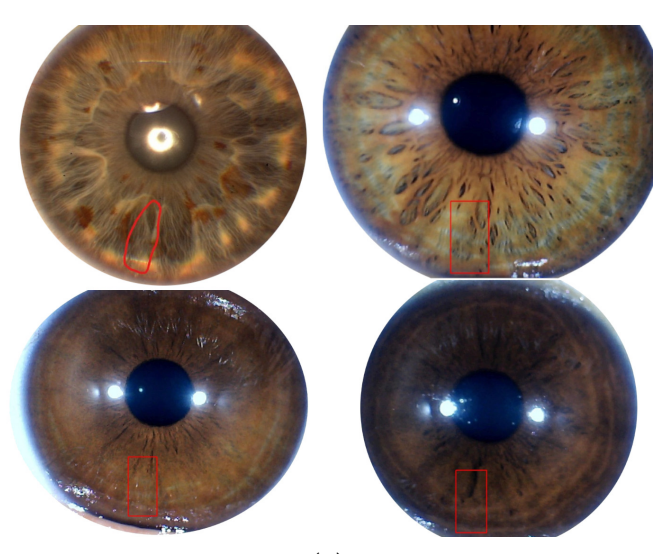

(a)

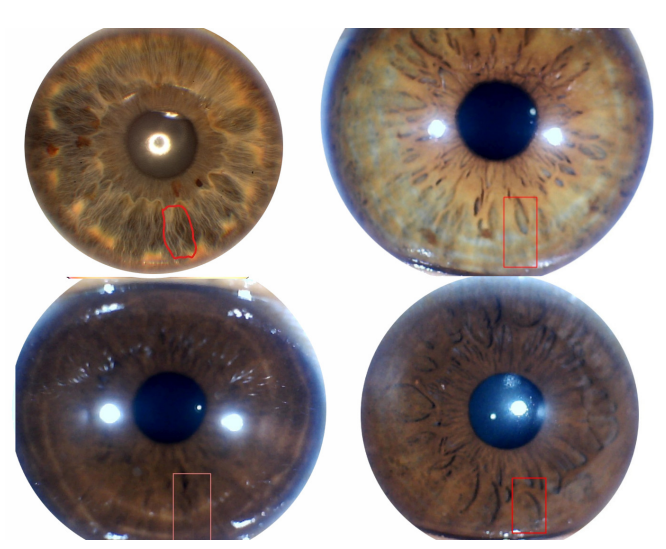

(b)

Figure 3. Iridology region of interest (ROI) Marks and patterns showing kidney problems (a) Right Eyes (b) Left Eyes. 
Iris images of subjects having chronic kidney problem contained the following patterns and marks: (a) A long solid black line. (b) One or more, large or small open lesion. (c) Change in color of the iris tissue. As kidney problems get worse, the GFR level decreases, and, similarly, the marks, lesions, and crypts appear in the iris in the corresponding region. Furthermore, in Figure 3 it can be clearly seen the variations in the iris pattern or colour of right and left eye irises. Change in the marks and patterns on the irises reflect the after-effects of chronic kidney disease.

\subsection{Iris-Acquisition System (IAS)}

The Iris-Acquisition System (shown in Figure 4) collects the data from different subjects while using a high-resolution iris camera along with the patient's detailed medical history and performs statistical study based on the chronic kidney problem and store it in the data-set. To acquire the data the IAS is linked with hospitals and medical labs. During iris acquisition, the subjects with chronic kidney disease are gathered and labeled. These labelings are based on subject medical reports and history with GFR $<30$. Figure 4 shows the IAS working environment, which acquires true RGB colored images in high resolution. The iris camera uses a charge-coupled device (CCD) based image sensor 24 Megapixel Digital Single Lens Reflex (DSLR) Canon Camera with a $100 \mathrm{~mm}$ Macro lens that gathers color images with a resolution up to $2560 \times 1920$ pixels. The macro lens configuration is configured specially for iridology having ISO settings between 100 to 800 and a narrow aperture that results in good exposure. The IAS has a USB interface that can interface easily with any computer device and allows for data to travel at an average of ten times the speed of the normal parallel port.

\subsection{Processing System}

The section describes the UCERD GPU-based supercomputer system architecture (shown in Figure 5), which is used to execute the ICKIS algorithm. UCERD GPU-based supercomputer is an Intel Xeon processors having enough processing power and speed to handle the intensive processing and Nvidia Pascal GPU accelerators. The UCERD GPU-based supercomputer system uses four nodes, and each node is equipped with 12 cores and two threads/cores, a total of 24 threads, and 2 NVidia-Pascal GPUs. The distributed nodes are interconnected using Gigabit interconnections and they utilize the CentOS Linux Operating System. This system has a peak performance of 48.5 Tera floating-point operations per second.

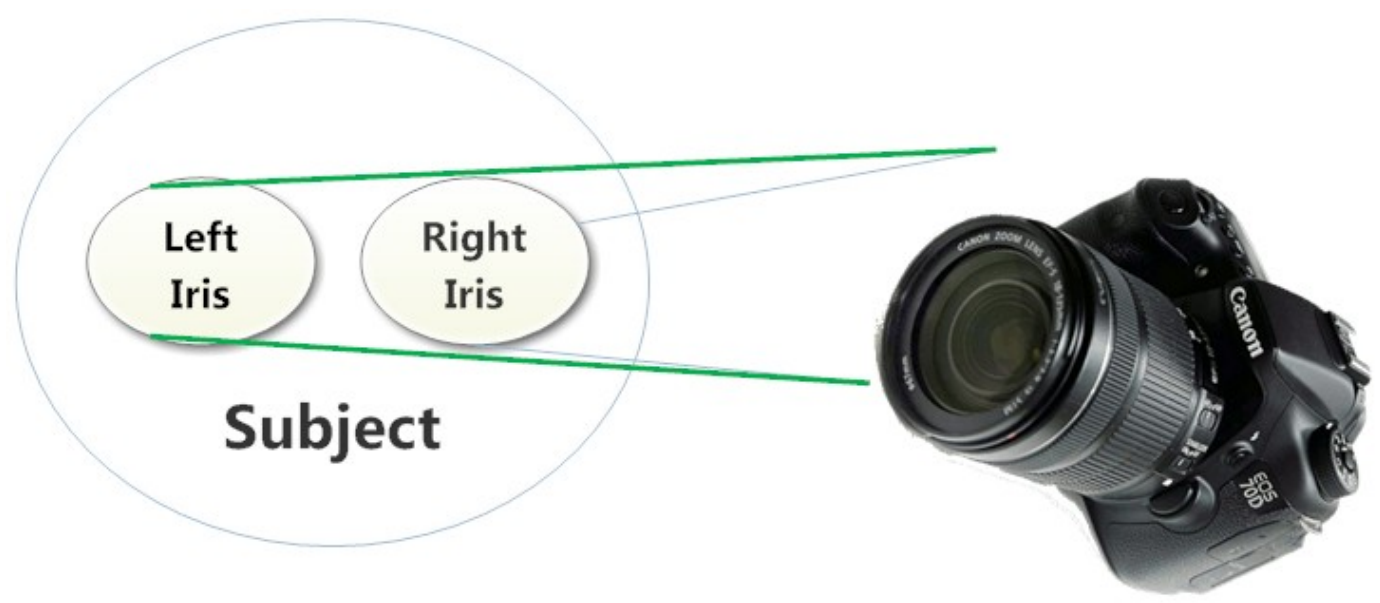

Figure 4. Photograph of Iris Acquisition System. 


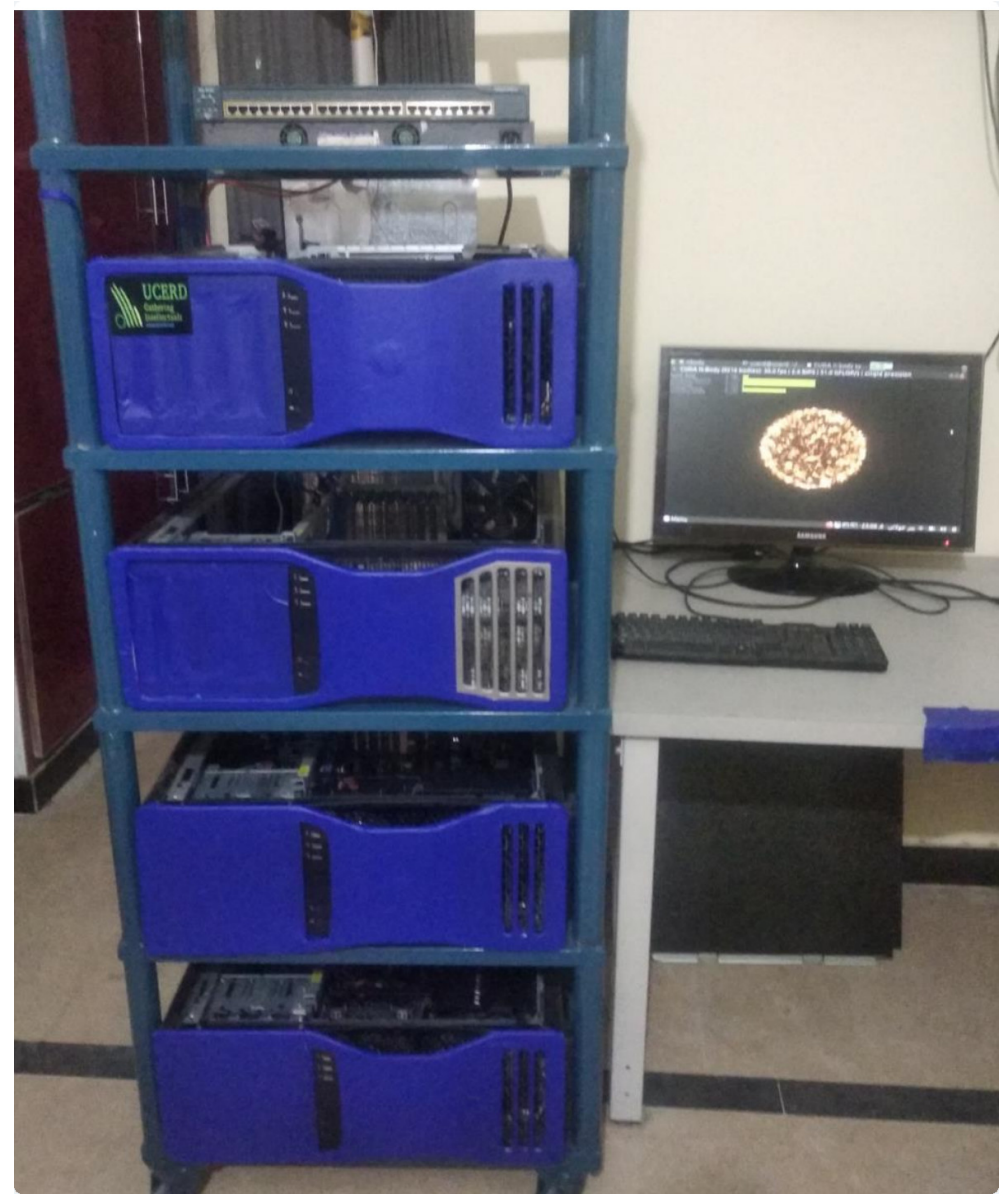

Figure 5. Photograph of UCERD GPU-based Supercomputing Cluster.

\subsection{Artificial Intelligence (AI) Algorithm}

Figure 6 shows the block diagram of the AI Algorithm. Python 3.6 programming language, OpenCV computer vision, and Tensor-Flow-2 deep learning framework are used to program the Iris-based Chronic Kidney Identification System (ICKIS) algorithm.

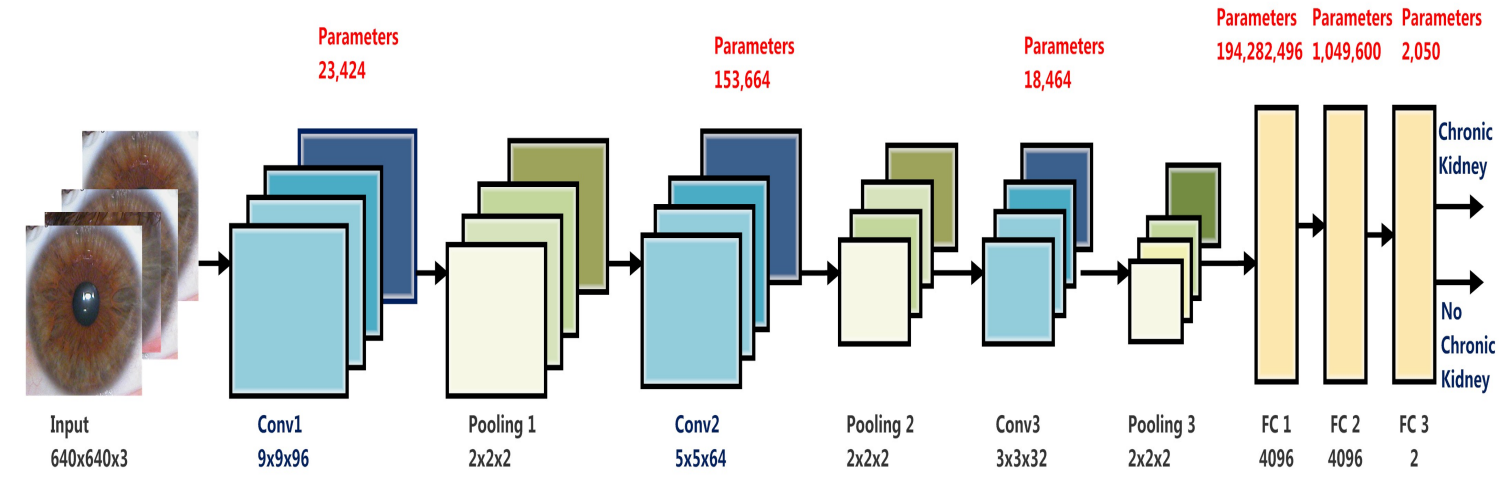

Figure 6. AI algorithm used to train and test the data-set for chronic kidney problem.

The conventional neural network $(\mathrm{CNN})$ is used in this research work to extract and classify core features automatically while using filters. These features are being extracted from the region of interest (ROI), excluding other iris areas. The size of the filter and weights were automatically adjust based on initial training results. Later regularization techniques are being applied, and the weights are adjusted for fine-tuning. It is noted that, as the filters increase from 96 for the input image, the targeted 
patterns and marks are not encoded. Additionally, the increase in filter size does not affect the accuracy, but increases the time. On the other hand, the weights of the filters are being added and adjusted based on real-time trails results. The featured information goes through the successive convolution filters and gets out increasingly purified. At the max-pooling stage $[63,64]$, the most appropriate features are extracted, and the fully connected layer at the end-stage is used for classification purposes. The AI algorithm has 195,529,698 trainable parameters. The parameter identification for the ICKIS algorithm is added by reading from the source and by real-time experiments-based experiences.

The input of the AI algorithm is training and testing data-sets that consist of iris images, and each image is labeled with healthy kidney and chronic kidney classes. The input resolution of our data-set is $2560 \times 1920 \times 3$, therefore the input layer resizes the data-set into $640 \times 640 \times 3$. The AI algorithm uses three convolution layers to extract the features of the images while using convolution filters, with $2 \times 2$ max-pooling. The first convolution layer applies 96 filters with a window size of $9 \times 9$. The pooling layer 1 (Pooling 1 ) takes the results of convolution layer 1 (Conv1) (as shown in Figure 6 ) and down samples the image to $320 \times 320$ by using $2 \times 2$ max-pooling having a stride of 2. Max pooling performs a reduction and over-fitting in dimensions of the image by taking the maximum pixel value of a grid. Later, the Conv2 [65] layer applies 64 filters having a window size of $5 \times 5$. The Conv 3 layer applies 32 filters with a window size of $3 \times 3$. The output of the convolution layer is four-dimensional; therefore, we add 2 Fully Connected (FC) layers that convert the input layer into two-dimensional. Later, a soft-max layer is added with each FC layer. Subsequently, the output of FC layers is connected with the final layer, which is the soft-max layer. The final layer is used to classify the image into one category out of two given categories according to the features of the image. The output of the ICKIS algorithm has two classes/categories chronic kidney and healthy kidney. The parameter identification for the ICKIS algorithm is added by reading from the source and by real-time experiments based experiences.

\section{Results and Discussion}

In this section, we perform the testing and validation of the proposed ICKIS system and discuss data-sets, accuracy, and performance of the algorithm. Afterwards, we compare our ICKIS algorithm with already existing algorithms. This section is divided into four subsections: the data-set; the training methodology; the validation and accuracy; and, comparison with other proposed algorithms.

\subsection{Iris Data-Set}

The data were gathered from the IIMCT-Pakistan Railway Hospital and NIRM-National Institute of Rehabilitation Medicine. With more than two different institutes collaborating in this study, all of the research publication ethics and anonymity of subjects are respected at all stages of the project. All parts of the data collection are carried out by skilled professionals (Biomedical Department, Riphah International University). The authors have carried out meetings with all parties and each group knows their role in the project. Regular meetings are held between all parties to foresee and plan for any issue that may arise.

A total of four thousand subjects are used in this research, in which 2000 subjects have chronic kidney disease and the remaining 2000 are subjects with healthy kidneys. The chronic kidney disease subjects are investigated through their medical reports and only those subjects are considered that have GFR $<30$. Ten images from each subject are taken with five images for the left eye and five images for the right eyes. Each iris image has a resolution of $2560 \times 1920 \times 3$ pixels.

The data-set (as shown in Table 1) holds 40,000 iris images of both left and right iris, out of which 20,000 images belong to healthy subjects, whereas the remaining 20,000 images belong to subjects having chronic kidney disease. The data-sets are further categorized into Training Data-Set and Testing Data-Set. Each Data-Set holds 20,000 iris images, out of which 50\% images comprise subjects with chronic kidney disease, and the remaining $50 \%$ images are of healthy subjects. 
Table 1. Training and Testing Data-Set.

\begin{tabular}{llll}
\hline Data-Set & $\begin{array}{l}\text { Healthy } \\
\text { Subjects/Images }\end{array}$ & $\begin{array}{l}\text { Chronic } \\
\text { Subjects/Images }\end{array}$ & $\begin{array}{l}\text { Total } \\
\text { Subjects/Images }\end{array}$ \\
\hline Training & $1000 / 10,000$ & $1000 / 10,000$ & $2000 / 20,000$ \\
\hline Testing & $1000 / 10,000$ & $1000 / 10,000$ & $2000 / 20,000$ \\
\hline Total & $2000 / 20,000$ & $2000 / 20,000$ & $4000 / 40,000$ \\
\hline
\end{tabular}

\subsection{Training Methodology}

In this section, we explain how the ICKIS AI algorithm (shown in Figure 6) is trained on Training Data-Set (Table 1) and UCERD-GPU based supercomputer. The AI algorithm has 195,529,698 trainable parameters. In order to train the AI algorithm, we applied data-level parallelism that divides the training data into multiple subsets, each set is executed on a separate node. To perform synchronization, the Stochastic Gradient Descent (SGD) is applied that incorporates the result of each computation with the AI algorithm. We have applied training of the ICKIS AI algorithm with stochastic gradient descent by utilizing the Horoward [66] deep learning toolkit. The distributed execution on a supercomputer system uses eight replicas each performing processing on an NVidia Pascal GPU. The training methodology on the UCERD-GPU based supercomputer takes $94 \mathrm{~min}$. to train the ICKIS AI algorithm. The training methodology provides a fast, scalable, intelligent, and high-performance computing based method for the primary diagnosing of chronic kidney disease.

\subsection{Validation and Accuracy}

The testing data-set (in Table 1) is used in order to validate the ICKIS. Because each subject has 10 images, the subject is considered to be a chronic kidney patient if the AI algorithm has chronic kidney patterns in 5 or more of its iris images. If the ICKIS AI algorithm detects chronic kidney problems either in the right or left iris of the subject, it is considered to have chronic kidney disease. In order to recognize the healthy kidneys, images of both eyes must have a healthy kidney function, so the subject is considered to be healthy if the AI algorithm has healthy kidney patterns for all of its ten iris images.

The results of the test subjects (1000 subjects with chronic kidney problems and 1000 subjects with healthy kidneys) in Table 2, respectively, show the correct classification, namely subjects with healthy kidney and chronic kidney is $95.4 \%$ and $98.2 \%$, respectively. On the other hand, the false classifications of subjects with a healthy kidney are $4.6 \%$.

False-negative classification is considered to be one of the most important factors in the performance of the designed classifier, and it is found to be $1.8 \%$. This percentage indicates that, out of 100 subjects with chronic kidney problems, almost two subjects may be misdiagnosed.

Table 2. Artificial Intelligence (AI) Algorithm outcomes of the testing data-set for healthy and chronic kidney.

\begin{tabular}{lll}
\hline & Healthy Kidney & Chronic Kidney \\
\hline Number of tested Subjects & 1000 & 1000 \\
\hline Correct Classified & 954 & 982 \\
\hline False Classified & 46 & 18 \\
\hline
\end{tabular}

The ICKIS AI algorithm is tested on a separate Testing Set (shown in Table 1). The results show (Figure 7) the accuracy of the ICKIS AI algorithm. The result shows that the algorithm identifies the chronic kidney subject with an accuracy of $96.8 \%$. The ICKIS algorithm identifies the imaging results of the iris scan having variable and non-specific patterns level of kidney problem. The algorithm can also reveal the evolution of kidney problems with the time and effect of medication on the patient. The creatinine test of the subjects verifies the results. 


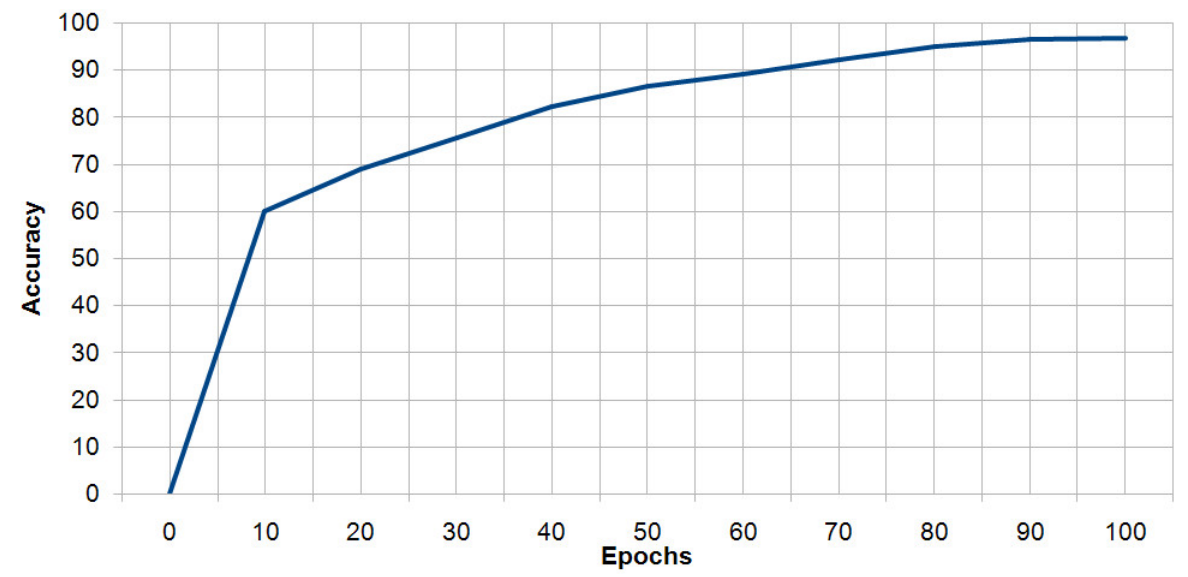

Figure 7. ICKIS AI Algorithm Accuracy on Supercomputer System.

The proposed approach is superior and give high accuracy because of the following reasons: (a) The focus is on the kidney critical stages (Stage 4 and Stage 5) while using iris images of the human eye. (b) The dataset is cleaned and labeled while using standard medical kidney diagnostic tools. (c) The AI model uses a deep CNN and high-performance computing.

\subsection{Comparison with Other Proposed Algorithms}

In this section, we compare our approach with existing iris-based kidney problem identification methods. The column "Author" of Table 3 shows the similar work that was done by the other authors on kidney. Seven different research work has been shown on kidney problems/diseases related to iridology in different times. The column data-set indicates the ratio of total kidney subjects to chronic ones. The total means healthy and chronic kidney subjects together in this column, while chronic kidney only implies chronic subjects from the relevant study work. In these research, the maximum data-set size is 400 , with 250 participants having chronic kidney disease. However, with 2000 chronic kidney disease subjects, our data collection has 4000 subjects. The accuracy column shows the percentage of subjects classified by means of iris images and algorithms as chronic kidney subjects. There is only one finding (of hemodialysis patients) that reveals the accuracy of both the left and right eyes separately and, to all others, both kidneys are considered together. From Table 3, the results show that the proposed ICKIS has $96.8 \%$ accuracy with an increased size of data-sets. This indicates that the findings obtained are indeed effective and promising. The results also conclude that the proposed ICKIS methodology is adaptable for big data-sets and it can give scaleable performance while using high-performance supercomputing systems.

Table 3. Comparison of sample size and accuracy for existing models and proposed model.

\begin{tabular}{lll}
\hline Author & Data-Set [Total/Chronic kidney] & Accuracy \\
\hline Hussein et al. [39] & $340 / 172$ & $82 \%$ \\
\hline S. Amerifar er al. [44] & $116 / 56$ & $82 \%$ \\
\hline Prayitno et al. [47] & $47 / 31$ & $76 \%$ \\
\hline Sitorus et al. [50] & $33 / 33$ & $90 \% \mathrm{R}, 94 \% \mathrm{~L}$ \\
\hline Shankar et al. [67] & $400 / 250$ & $96.63 \%$ \\
\hline Putra AP et al. [68] & $27 / 12$ & $93.75 \%$ \\
\hline DNP Rahayu et al. [69] & $20 / 20$ & $95 \%$ \\
\hline Proposed Method & $4000 / 2000$ & $96.80 \%$ \\
\hline
\end{tabular}




\section{Conclusions and Future Work}

In this work, an alternative medical diagnostic method, called the Intelligent Iris-based Chronic Kidney Identification System (ICKIS), is proposed. ICKIS detects chronic kidney disorders at an early stage while using an artificial intelligence algorithm and iridology. The proposed ICKIS uses human iris as input and a deep neural network-based algorithm, in order to determine whether or not the subject has a chronic kidney problem. ICKIS has tested over 2000 subjects and the findings conclude that the device categorized subjects as healthy kidney and chronic kidney with an accuracy of $96.8 \%$. The ICKIS algorithm is trained and tested by a GPU based distributed computing machine.

In the future, we shall continue to detect more renal problems with our AI algorithm. We aim to find a method for assessing the problem of the chronic kidney for both kidneys independently. This provides a pre-diagnosis method and a better treatment of early stage kidney disease. We are now working to build and make our iris data-sets accessible to the research community for advanced health-care applications.

Author Contributions: Conceptualization, T.H. and A.H.; Data curation, A.H.; Formal analysis, A.H.; Funding acquisition, T.H.; Investigation, S.M. and A.H.; Methodology, S.M. and T.H.; Project administration, T.H.; Resources, T.H. and E.A.; Software, A.H. and U.W.; Supervision, T.H.; Validation, S.M. and U.W.; Visualization, U.W.; Writing—original draft, S.M.; Writing—review \& editing, S.M., T.H., A.H., U.W. and U.A. All authors have read and agreed to the published version of the manuscript.

Funding: This work is supported by the Higher Education Commission (HEC) of Pakistan under the Technology Development Fund with project Number TDF03-097 and National Research Program for Universities (NRPU) with project grant no. 8153/Federal/NRPU/R\&D/HEC/2017.

Acknowledgments: The authors would like to thank the Unal Color of Education Research and Development (UCERD), Private Limited Islamabad, and Barcelona Supercomputing Center Spain for the support.

Conflicts of Interest: The authors declare no conflict of interest.

\section{References}

1. Jones, T.C.; Hard, G.C.; Mohr, U. Urinary System; Springer: Berlin/Heisenberg, Germany, 2013.

2. Kurtz, I.; Maher, T.; Hulter, H.N.; Schambelan, M.; Sebastian, A. Effect of diet on plasma acid-base composition in normal humans. Kidney Int. 1983, 24, 670-680. [CrossRef] [PubMed]

3. Baranowska, I.; Płonka, J. Determination of biogenic amines and vitamins in urine samples with HPLC. J. Liq. Chromatogr. Relat. Technol. 2008, 31, 2974-2987. [CrossRef]

4. Kirchmann, H.; Pettersson, S. Human urine-chemical composition and fertilizer use efficiency. Fertil. Res. 1994, 40, 149-154. [CrossRef]

5. Veeralingam, S.; Sahatiya, P.; Badhulika, S. Low cost, flexible and disposable SnSe2 based photoresponsive ammonia sensor for detection of ammonia in urine samples. Sens. Actuators B Chem. 2019, 297, 126725. [CrossRef]

6. Wyss, M.; Kaddurah-Daouk, R. Creatine and creatinine metabolism. Physiol. Rev. 2000, 80, 107-213.

7. Yaroshenko, I.; Kirsanov, D.; Kartsova, L.; Sidorova, A.; Borisova, I.; Legin, A. Determination of urine ionic composition with potentiometric multisensor system. Talanta 2015, 131, 556-561. [CrossRef]

8. Abbrecht, P.H.; Malvin, R.L. Effects of GFR and renal plasma flow on urine osmolarity. Am. J. Physiol. Leg. Content 1961, 201, 754-758. [CrossRef]

9. Griggers, S.; Paccamonti, D.; Thompson, R.; Eilts, B. The effects of pH, osmolarity and urine contamination on equine spermatozoal motility. Theriogenology 2001, 56, 613-622. [CrossRef]

10. Schrier, R.W. Diseases of the Kidney and Urinary Tract; Lippincott Williams \& Wilkins: Philadelphia, PA, USA, 2007; Volume 1.

11. Romagnani, P.; Remuzzi, G.; Glassock, R.; Levin, A.; Jager, K.J.; Tonelli, M.; Massy, Z.; Wanner, C.; Anders, H.J. Chronic kidney disease. Nat. Rev. Dis. Prim. 2017, 3, 17088. [CrossRef]

12. Levin, A.; Tonelli, M.; Bonventre, J.; Coresh, J.; Donner, J.A.; Fogo, A.B.; Fox, C.S.; Gansevoort, R.T.; Heerspink, H.J.; Jardine, M. Global kidney health 2017 and beyond: A roadmap for closing gaps in care, research, and policy. Lancet 2017, 390, 1888-1917. [CrossRef] 
13. Levin, A. The clinical epidemiology of cardiovascular diseases in chronic kidney disease: Clinical epidemiology of cardiovascular disease in chronic kidney disease prior to dialysis. In Seminars in Dialysis; Wiley Online Library; Blackwell Science Inc.: Oxford, UK, 2003; Volume 16, pp. 101-105.

14. Wilson, B.J.; Watson, M.S.; Prescott, G.J.; Sunderland, S.; Campbell, D.M.; Hannaford, P.; Smith, W.C.S. Hypertensive diseases of pregnancy and risk of hypertension and stroke in later life: Results from cohort study. BMJ 2003, 326, 845. [CrossRef] [PubMed]

15. Fauci, A.S. The human immunodeficiency virus: Infectivity and mechanisms of pathogenesis. Science 1988, 239, 617-622. [CrossRef] [PubMed]

16. World Health Organization. World Malaria Report 2015; World Health Organization: Geneva, Switzerland, 2016.

17. Naghavi, M.; Wang, H.; Lozano, R.; Davis, A.; Liang, X.; Zhou, M. GBD 2013 Mortality and Causes of Death Collaborators. Global, regional, and national age-sex specific all-cause and cause-specific mortality for 240 causes of death, 1990-2013: A systematic analysis for the Global Burden of Disease Study 2013. Lancet 2015, 385, 117-171.

18. Liyanage, T.; Ninomiya, T.; Jha, V.; Neal, B.; Patrice, H.M.; Okpechi, I.; Zhao, M.h.; Lv, J.; Garg, A.X.; Knight, J. Worldwide access to treatment for end-stage kidney disease: A systematic review. Lancet 2015, 385, 1975-1982. [CrossRef]

19. Mehta, R.L.; Cerdá, J.; Burdmann, E.A.; Tonelli, M.; García-García, G.; Jha, V.; Susantitaphong, P.; Rocco, M.; Vanholder, R.; Sever, M.S. International Society of Nephrology's 0by25 initiative for acute kidney injury (zero preventable deaths by 2025): A human rights case for nephrology. Lancet 2015, 385, 2616-2643. [CrossRef]

20. Luyckx, V.A.; Tonelli, M.; Stanifer, J.W. The global burden of kidney disease and the sustainable development goals. Bull. World Health Organ. 2018, 96, 414. [CrossRef]

21. Mischak, H. Autosomal-Dominant Polycystic Kidney Disease (ADPKD). US Patent App. 13/140,106, 6 July 2011.

22. Cattran, D.C.; Feehally, J.; Cook, H.T.; Liu, Z.H.; Fervenza, F.C.; Mezzano, S.A.; Floege, J.; Nachman, P.H.; Gipson, D.S.; Praga, M. Kidney disease: Improving global outcomes (KDIGO) glomerulonephritis work group. KDIGO clinical practice guideline for glomerulonephritis. Kidney Int. Suppl. 2012, 2, 139-274.

23. Murray, T.; Goldberg, M. Chronic interstitial nephritis: Etiologic factors. Ann. Intern. Med. 1975, 82, 453-459. [CrossRef]

24. Foley, R.N.; Murray, A.M.; Li, S.; Herzog, C.A.; McBean, A.M.; Eggers, P.W.; Collins, A.J. Chronic kidney disease and the risk for cardiovascular disease, renal replacement, and death in the United States Medicare population, 1998 to 1999. J. Am. Soc. Nephrol. 2005, 16, 489-495. [CrossRef]

25. Chadban, S.J.; Atkins, R.C. Glomerulonephritis. Lancet 2005, 365, 1797-1806. [CrossRef]

26. Gross, J.L.; De Azevedo, M.J.; Silveiro, S.P.; Canani, L.H.; Caramori, M.L.; Zelmanovitz, T. Diabetic nephropathy: Diagnosis, prevention, and treatment. Diabetes Care 2005, 28, 164-176. [CrossRef] [PubMed]

27. Tim Newman. Symptoms, Causes, and Treatment of Chronic Kidney Disease. 2017. Available online: https:/ / www.medicalnewstoday.com/articles/172179 (accessed on 3 October 2020).

28. Stevens, L.A.; Levey, A.S. Measured GFR as a confirmatory test for estimated GFR. J. Am. Soc. Nephrol. 2009, 20, 2305-2313. [CrossRef] [PubMed]

29. Avorn, J.; Winkelmayer, W.C.; Bohn, R.L.; Levin, R.; Glynn, R.J.; Levy, E.; Owen, W., Jr. Delayed nephrologist referral and inadequate vascular access in patients with advanced chronic kidney failure. J. Clin. Epidemiol. 2002, 55, 711-716. [CrossRef]

30. Levin, A.; Stevens, P.E. Early detection of CKD: The benefits, limitations and effects on prognosis. Nat. Rev. Nephrol. 2011, 7, 446-457. [CrossRef] [PubMed]

31. Jungers, P.; Zingraff, J.; Albouze, G.; Chauveau, P.; Page, B.; Hannedouche, T.; Man, N. Late referral to maintenance dialysis: Detrimental consequences. Nephrol. Dial. Transplant. 1993, 8, 1089-1093. [PubMed]

32. Perazella, M.A.; Khan, S. Increased mortality in chronic kidney disease: A call to action. Am. J. Med. Sci. 2006, 331, 150-153. [CrossRef]

33. Roubicek, C.; Brunet, P.; Huiart, L.; Thirion, X.; Leonetti, F.; Dussol, B.; Jaber, K.; Andrieu, D.; Ramananarivo, P.; Berland, Y. Timing of nephrology referral: Influence on mortality and morbidity. Am. J. Kidney Dis. 2000, 36, 35-41. [CrossRef]

34. Jonas, W.B. Alternative medicine-Learning from the past, examining the present, advancing to the future. JAMA 1998, 280, 1616-1618. [CrossRef] 
35. Shon, H.S.; Batbaatar, E.; Kim, K.O.; Cha, E.J.; Kim, K.A. Classification of Kidney Cancer Data Using Cost-Sensitive Hybrid Deep Learning Approach. Symmetry 2020, 12, 154. [CrossRef]

36. MacLennan, A.H.; Wilson, D.H.; Taylor, A.W. Prevalence and cost of alternative medicine in Australia. Lancet 1996, 347, 569-573. [CrossRef]

37. Jensen, B. Iridology Simplified, 5th ed.; Book Pub Co.: Summertown, TN, USA, 2012.

38. Lodin, A.; Demea, S. Design of an iris-based medical diagnosis system. In Proceedings of the 2009 International Symposium on Signals, Circuits and Systems, Iasi, Romania, 9-10 July 2009; pp. 1-4.

39. Hussein, S.E.; Hassan, O.A.; Granat, M.H. Assessment of the potential iridology for diagnosing kidney disease using wavelet analysis and neural networks. Biomed. Signal Process. Control 2013, 8, 534-541. [CrossRef]

40. Hussain, T.; Haider, A.; Muhammad, A.M.; Agha, A.; Khan, B.; Rashid, F.; Raza, M.S.; Din, M.; Khan, M.; Ullah, S. An Iris based Lungs Pre-diagnostic System. In Proceedings of the 2019 2nd International Conference on Computing, Mathematics and Engineering Technologies (iCoMET), Sukkur, Pakistan, 30-31 January 2019; pp. 1-5. [CrossRef]

41. Li, Y.H.; Aslam, M.S.; Yang, K.L.; Kao, C.A.; Teng, S.Y. Classification of Body Constitution Based on TCM Philosophy and Deep Learning. Symmetry 2020, 12, 803. [CrossRef]

42. Jha, V. Current status of end-stage renal disease care in India and Pakistan. Kidney Int. Suppl. 2013, 3, 157-160. [CrossRef]

43. Pedersen, S.J.K. Circular Hough Transform; Aalb. Univ. Vision, Graph. Interact. Syst.; University in Aalborg: Aalborg, Denmark, 2007; Volume 123.

44. Amerifar, S.; Targhi, A.T.; Dehshibi, M.M. Iris the picture of health: Towards medical diagnosis of diseases based on iris pattern. In Proceedings of the 2015 Tenth International Conference on Digital Information Management (ICDIM), Jeju, Korea, 21-23 October 2015; pp. 120-123.

45. You, J.; Chen, B. New approach to retinal image enhancement based on Hessian matrix. Jisuanji Yingyong/J. Comput. Appl. 2011, 31, 1560-1562. [CrossRef]

46. Frangi, A.F.; Niessen, W.J.; Vincken, K.L.; Viergever, M.A. Multiscale vessel enhancement filtering. In Proceedings of the International Conference on Medical Image Computing and Computer-Assisted Intervention, Cambridge, MA, USA, 11-13 October 1998; pp. 130-137.

47. Prayitno, A.; Wibawa, A.D.; Purnomo, M.H. Early detection study of Kidney Organ Complication caused by Diabetes Mellitus using iris image color constancy. In Proceedings of the 2016 International Conference on Information \& Communication Technology and Systems (ICTS), Surabaya, Indonesia, 12 October 2016; pp. 146-149.

48. Ebner, M. Color Constancy; John Wiley \& Sons: Hoboken, NJ, USA, 2007; Volume 7.

49. Comon, P. Independent component analysis, a new concept? Signal Process. 1994, 36, 287-314. [CrossRef]

50. Sitorus, M.A.; Purnomo, M.H.; Wibawa, A.D. Iris image analysis of patient Chronic Renal Failure (CRF) using watershed algorithm. In Proceedings of the 2015 4th International Conference on Instrumentation, Communications, Information Technology, and Biomedical Engineering (ICICI-BME), Bandung, Indonesia, 2-3 November 2015; pp. 54-58.

51. Samant, P.; Agarwal, R. Machine learning techniques for medical diagnosis of diabetes using iris images. Comput. Methods Programs Biomed. 2018, 157, 121-128. [CrossRef] [PubMed]

52. Passarella, R.; Erwin, E.; Fachrurrozi, M.; Sutarno, S. Development of iridology system database for colon disorders identification using Image processing. Indian J. Bioinform. Biotechnol. 2013, 2, 100-103.

53. Banzi, J.F.; Xue, Z. An automated tool for non-contact, real time early detection of diabetes by computer vision. Int. J. Mach. Learn. Comput. 2015, 5, 225. [CrossRef]

54. About: UCERD Private Limited Islamabad. 2018. Available online: http://ucerd.com/my_uploads/pdfs/ info/UCERD.pdf (accessed on 17 September 2020).

55. Iridology Research Group (IRG). 2018. Available online: http://ucerd.com/Iridology_Research_Group.php (accessed on 22 September 2020).

56. Hussain, T.; Haider, A.; Taleb-Ahmed, A. A Heterogeneous Multi-Core Based Biomedical Application Processing System and Programming Toolkit. J. Signal Process. Syst. 2019, 91, 963-978. [CrossRef]

57. Haider, A.; Hussain, T.; Agha, A.; Khan, B.; Rashid, F.; Muzamil, S.; Ahmed, A.T.; Alharbi, S.A.; Ayguade, E. An Iris based Smart System for Stress Identification. In Proceedings of the 2019 International Conference on Electrical, Communication, and Computer Engineering (ICECCE), Swat, Pakistan, 24-25 July 2019; pp. 1-5. 
58. Hussain, T.; Palomar, O.; Cristal, A.; Ayguade, E.; Amna, H. ViPS: Visual Processing System for Medical Imaging. In Proceedings of the 2015 8th International Congress on Image and Signal Processing (CISP 2015) and the 2015 8th International Conference on BioMedical Engineering and Informatics (BMEI 2015), Shenyang, China, 14-16 October 2015.

59. Hussain, T.; Haider, A. PGC: A pattern-based graphics controller. Int. J. Circuits Archit. Des. 2014, 1, 117-140.

60. Hussain, T. ViPS: A novel visual processing system architecture for medical imaging. Biomed. Signal Process. Control 2017, 38, 293-301. [CrossRef]

61. Hussain, T.; Haider, A.; Cristal, A.; Ayguadé, E. EMVS: Embedded Multi Vector-core System. J. Syst. Archit. 2018, 87, 12-22. [CrossRef]

62. Levey, A.S.; Eckardt, K.U.; Tsukamoto, Y.; Levin, A.; Coresh, J.; Rossert, J.; Zeeuw, D.D.; Hostetter, T.H.; Lameire, N.; Eknoyan, G. Definition and classification of chronic kidney disease: A position statement from Kidney Disease: Improving Global Outcomes (KDIGO). Kidney Int. 2005, 67, 2089-2100. [CrossRef] [PubMed]

63. Krizhevsky, A.; Sutskever, I.; Hinton, G.E. Imagenet classification with deep convolutional neural networks. Commun. ACM 2017, 60, 84-90. [CrossRef]

64. Oh, S.L.; Vicnesh, J.; Ciaccio, E.J.; Yuvaraj, R.; Acharya, U.R. Deep convolutional neural network model for automated diagnosis of schizophrenia using EEG signals. Appl. Sci. 2019, 9, 2870. [CrossRef]

65. Jaderberg, M.; Vedaldi, A.; Zisserman, A. Speeding up convolutional neural networks with low rank expansions. arXiv 2014, arXiv:1405.3866.

66. Sergeev, A.; Del Balso, M. Horovod: Fast and easy distributed deep learning in TensorFlow. arXiv 2018, arXiv:1802.05799.

67. Shankar, K.; Manickam, P.; Devika, G.; Ilayaraja, M. Optimal Feature Selection for Chronic Kidney Disease Classification using Deep Learning Classifier. In Proceedings of the 2018 IEEE International Conference on Computational Intelligence and Computing Research (ICCIC), Madurai, India, 13-15 December 2018; pp. 1-5.

68. Putra, A.P.; Sutojo, T. Identifikasi Penurunan Kondisi Fungsi Organ Ginjal Melalui Iris Mata Menggunakan Metode Jaringan Syaraf Tiruan Learning Vector Quantization. Fakultas Ilmu Komputer Universitas Dian Nuswantoro 2014, 13, 45-52.

69. Rahayu, D.N.P.; Isnanto, R.R.; Hidayatno, A. Aplikasi Pendiagnosis Gangguan Ginjal Melalui Citra Iris Mata Menggunakan Metode Segmentasi Berdasar Deteksi Tepi. Transient J. Ilm. Tek. Elektro 2013, 2, $283-288$.

Publisher's Note: MDPI stays neutral with regard to jurisdictional claims in published maps and institutional affiliations.

(C) 2020 by the authors. Licensee MDPI, Basel, Switzerland. This article is an open access article distributed under the terms and conditions of the Creative Commons Attribution (CC BY) license (http://creativecommons.org/licenses/by/4.0/). 